\title{
Animasi Interktif Media Pembelajaran Bahasa Jepang Dasar Untuk Siswa Sekolah Menengah Kejuruan
}

\author{
Ahmad Wildan Syuja'ie ${ }^{1}$, Sari Hartini ${ }^{2,}{ }^{*}$, Fajar Agustini ${ }^{1}$ \\ * Korespondensi: e-mail: sari.shi@nusamandiri.ac.id
}

\begin{abstract}
Program Studi Sistem Informasi STMIK Nusa Mandiri, JI. Damai No.8 Warung Jati Barat (Margasatwa), Jakarta Selatan, Telp (021) 78839513 Fax.(021) 78839421, email:

ahmadwil1310@nusamandiri.ac.id; fajar.fgt@nusamandiri.ac.id

2 Program Studi Teknik Informatika, STMIK Nusa Mandiri, Jl. Kramat Raya No.18, RT.5/RW.7, Kwitang, Kec. Senen, Kota Jakarta Pusat, Daerah Khusus lbukota Jakarta 10420, Telp (021) 31908575, e-mail: sari.shi@nusamandiri.ac.id
\end{abstract}

Submitted: 4 Maret 2020 Revised: 25 Maret 2020 Accepted: 15 April 2020 Published: 20 Mei 2020

\begin{abstract}
In the world of education in Indonesia today, a development of information technology now makes many schools in Indonesia begin to apply many modern learning media based on information technology, so that the development of learning media will continue to change and will progress in the world of education. Advances in information technology can also change foreign language learning systems, one of which is Japanese which has 3 different writings. Data collection that has been done to obtain data is to look for sources of accurate information related to the Japanese language learning process at school, so that the writer can know and understand the advantages and disadvantages in the teaching and learning process at school. Many students find it difficult to learn Japanese because their writing is fairly difficult to learn. In addition, the lack of practice or Japanese language procedures is also a very influential thing in teaching and learning in school.
\end{abstract}

Keywords: Japanese Language, Learning Media, Interactive Animation.

\section{Abstrak}

Dalam dunia pendidikan di indonesia saat ini, sebuah perkembangan teknologi informasi sekarang membuat banyak sekolah di indonesia mulai menerapkan banyak media pembelajaran modern berbasis teknologi informasi, sehingga perkembangan media pembelajaran akan terus berubah dan akan mengalami kemajuan dalam lingkungan dunia pendidikan. Kemajuan teknologi informasi juga dapat merubah sistem pembelajaran bahasa asing, salah satunya yaitu bahasa jepang yang dimana bahasa ini memiliki 3 tulisan yang berbeda. Pengumpulan data yang telah dilakukan untuk mendapatkan data adalah dengan mencari sumber informasi yang akurat terkait dengan proses pembelajaran bahasa jepang disekolah, agar penulis dapat mengetahui dan memahami kelebihan dan kekurangan dalam proses belajar mengajar disekolah. Banyak para pelajar yang sulit untuk mempelajari bahasa jepang karena tulisannya yang terbilang sulit dipelajari. Selain itu kurangnya praktek atau tata cara berbahasa jepang juga merupakan suatu hal yang sangat berpengaruh dalam pola belajar mengajar disekolah.

Kata kunci: Bahasa Jepang, Media Pembelajaran, Animasi Interaktif.

\section{Pendahuluan}

Dalam dunia pendidikan di indonesia saat ini, sebuah perkembangan teknologi informasi sekarang membuat banyak sekolah di indonesia mulai menerapkan banyak media pembelajaran modern berbasis teknologi informasi, sehingga perkembangan media pembelajaran akan terus berubah dan akan mengalami kemajuan dalam lingkungan dunia pendidikan. Kemajuan teknologi informasi juga dapat merubah sistem pembelajaran bahasa asing (Ameliola \& Dwiyudha Nugraha, 2013), salah satunya yaitu bahasa jepang yang dimana bahasa ini memiliki 3 tulisan yang berbeda diantaranya adalah katakana, hiragana, dan kanji. 
Bahasa Jepang merupakan salah satu bahasa yang sulit (Nugroho et al., 2012). Meskipun begitu, bahasa jepang kian sangat populer dan disukai di banyak negara. Itu sebabnya kenapa banyak para pelajar yang mengalami kesulitan dalam mempelajari bahasa jepang, karena bahasa jepang sendiri mempunyai 3 tulisan yang berbeda dengan makna yang berbeda pula.

Dalam dunia pendidikan sebuah perkembangan animasi dapat membantu para guru dalam penyampaian materi secara interaktif dalam sebuah program pembelajaran dengan menggunakan suatu program komputer, salah satunya yaitu program media animasi interaktif (Purnama, 2012).

Maka atas dasar itulah skripsi "Animasi Interaktif Media Pembelajaran Bahasa Jepang Dasar Untuk Siswa Sekolah Menengah Kejuruan“ ini dibuat. Program aplikasi yang telah dibuat ini diharapkan dapat menjelaskan semua dasar yang perlu dipelajari dalam bahasa jepang sehingga pelajar akan mudah mempelajari dasar bahasa jepang (Soepomo, 2013).

\section{Metode Penelitian}

Dalam penelitian ini penulis menggunakan metode pengembangan MDLC (Multimedia Development Life Cycle). Model pengembangan yang digunakan dalam program ini yaitu model pengembangan multimedia versi Luther. Menurut (Komarudin \& Noor, 2017) pengembangan aplikasi multimedia dilakukan berdasarkan 6 tahap, yaitu : Concept, Design, Material Collecting, Assembly, Testing, dan Distribution (Implementation). Adapun pengertiannya sebagai berikut: (a) Concept, Tahap konsep (Concept) yaitu untuk menentukan sebuah tujuan, termasuk identifikasi pengguna atau pemakai, jenis aplikasi seperti (presentasi, interaktif dan lain-lain), poin tujuan aplikasi (informasi, hiburan, pelatihan, dan lain-lain) dan spesifikasi umum lainnya. Dasar aturan dari perancangan ini ditentukan pada tahap ini, seperti besar, kecil, ukuran program aplikasi, target dan lainnya. (b) Design, Maksud dari sebuah tahapan perancangan adalah untuk membuat sebuah spsifikasi secara rinci mengenai tentang arsitektur sebuah proyek, serta gaya dan kebutuhan material untuk proyek yang akan dibuat dengan menggunakan program visio. (c) Material Collecting, Pada tahap ini pengumpulan bahan (material collecting) akan dilakukan dengan cara pengumpulan bahan misalnya bahan clipart, bahan image, bahan animasi, bahan audio, bahan video, begitu juga pembuatan sebuah gambar, grafik, foto dan lainnya yang dibutuhkan untuk ke tahap berikutnya, bahan yang diperoleh akan diambil dari berbagai sumber. (d) Assembly, Tahap Pembuatan (Assembly) merupakan sebuah tahap dimana seluruh objek multimedia akan dibuat. (e) Testing, Tahap Tes (Testing) dilakukan setelah program selesai dari tahap pembuatan dan seluruh data telah dimasukan. Fungsi dari pengetesan adalah untuk memastikan agar hasil dari pembuatan program multimedia sesuai dengan apa yang telah direncanakan.Satu hal yang tidak kalah penting yaitu program harus berjalan dengan baik dilingkungan user, user akan merasakan kemudahan serta manfaat dari program tersebut dan dapat menggunakan sendiri. Ditahap ini penulis menggunakan white box testing, dan black box testing sebagai metode pengujian 
program. (f) Distribution, Pada tahap ini akan dilakukan implementasi serta evaluasi terhadap aplikasi multimedia pembelajaran mengenal bahasa jepang.

\section{Hasil dan Pembahasan}

\subsection{Analisa Kebutuhan Sistem}

Dalam merancang media pembelajaran bahasa jepang harus berpedoman pada karakteristik software, yaitu: (a) Format, Dalam program media pembelajaran bahasa jepang, program dibuat dalam format executable (.exe) agar program dapat berjalan dalam komputer dengan sistem operasi windows. Program juga disediakan dalam format app dan swf. (b) Rules, Pada media pembelajaran bahasa jepang ini terdapat 7 menu, yaitu materi, evaluasi, kosakata, profil, budaya, bantuan dan keluar. Menu materi mempunyai 4 sub menu diantaranya menu huruf hiragana, menu huruf katakana, menu huruf kanji, dan menu berbicara bahasa jepang. Pada menu huruf hiragana, huruf katakana, dan huruf kanji terdapat simulasi tentang tata cara penulisan huruf hiragana, huruf katakana, dan huruf kanji yang baik dan benar. Sedangkan menu berbicara bahasa jepang mempunyai 4 sub menu diantaranya adalah menu salam, menu percakapan, menu perkenalan, dan menu pertanyaan. Menu salam menampilkan tata cara berbahasa jepang tentang pengucapan salam. Menu percakapan menampilkan contoh percakapan berbahasa jepang. Menu perkenalan menampilkan tata cara perkenalan dalam berbahasa jepang. Menu pertanyaan menampilkan tata cara bertanya dalam berbahasa jepang. Selanjutnya menu evaluasi mempunyai 1 sub menu yaitu menu latihan yang menampilkan tentang latihan soal. Menu kosakata menampilkan tentang kosakata bahasa jepang. Menu profil menampilkan tentang profil pembuat program. Menu budaya menampilkan video tentang tradisi budaya jepang. Menu bantuan menampilkan tombol yang digunakan dalam aplikasi atau program. Sedangkan menu keluar untuk mengakhiri program. (c) Policy, Dalam program media pembelajaran bahasa jepang terdapat pertanyaan pada menu latihan yang memiliki bobot nilai 10 , maka setiap pertanyaan yang benar dikalikan dengan bobot nilai dan score menunjukan jumlah yang dijawab dengan benar. (d), Scenario, Scenario dalam program ini terdapat enam menu utama diantaranya, menu materi, menu evaluasi, menu kosakata, menu profil, menu budaya, menu bantuan, dan menu keluar. (e) Event/Challenge, Dalam program media pembelajaran bahasa jepang ini terdapat latihan soal dengan 10 pertanyaan yang harus dijawab dalam waktu 10 menit agar dapat menyelesaikan latihan soal tersebut. untuk mengetahui daya ingat user. (f) Roles, Pembelajaran ini diharuskan user untuk menjawab 10 pertanyaan berdasarkan dengan materi yang ada. (g) Decisions, Sebuah keputusan yang dapat dibuat user dalam hal ini adalah user dapat menentukan pilihan menu mana yang akan akan buka atau ingin di pelajari. (h) Level, Setiap pertanyaan memiliki bobot nilai 10 yang nantinya akan dikalikan dengan jumlah jawaban yang benar dari setiap pertanyaan. (i) Score Model, Dalam menu latihan terdapat 10 pertanyaan dimana user di berikan waktu 10 menit untuk menyelesaikan pertanyaan dan apabila 1 pertanyaan bernilai score 10 jika jawaban benar, dan score 0 jika jawaban salah. Total nilai akan terlihat diakhir sesi dan isi sesuai dengan jawaban yang telah user jawab dengan benar. (j) Indicator, Indikasi 
penentu sebuah keberhasilan media pembelajaran bahassa jepang ini adalah apabila user dapat menjawab 10 pertanyaan dengan benar. (k) Symbol, Sebagai penunjuk ke state berikutnya atau ke state sebelumnya digunakan tombol kembali, selain itu juga terdapat tomboltombol pada menu yang digunakan untuk menuju ke menu-menu yang disediakan seperti menu berikutnya.

\subsection{Perancangan Storyboard}

Perancangan Storyboard program media pembelajaran bahasa jepang yang telah dibuat. Berikut ini salah satu storyboard yang ada pada program animasi yang telah penulis buat yaitu intro, menu utama, menu materi, dan menu latihan soal:

Berikut ini gambar storyboard intro untuk penggambaran awal pada media interaktif pembelajaran Bahasa jepang dijalankan seperti yang dijelaskan pada tabel berikut:

Tabel 1. Storyboard Intro

\begin{tabular}{|c|c|c|}
\hline Visual & Sketsa & Audio \\
\hline $\begin{array}{lr}\text { Tampilan } & \text { sebelum } \\
\text { masuk ke menu utama } & \text { tulisan } \\
\text { dengan } & \text { perancangan } \\
\text { interaktif } & \text { media } \\
\text { pembelajaran } & \text { Bahasa } \\
\text { jepang dasar untuk } \\
\text { SMK dengan satu } \\
\text { tombol masuk dengan } \\
\text { masuk ke menu }\end{array}$ & MASUK & Senbon Zakura.mp3 \\
\hline
\end{tabular}

Sumber: Hasil Penelitian (2019)

Berikut ini gambar storyboard menu utama menggambarkan tentang tampilan menu utama yang akan digunakan pada saat masuk scne seperti yang dijelaskan pada tabel berikut:

Tabel 2. Storyboard Menu Utama

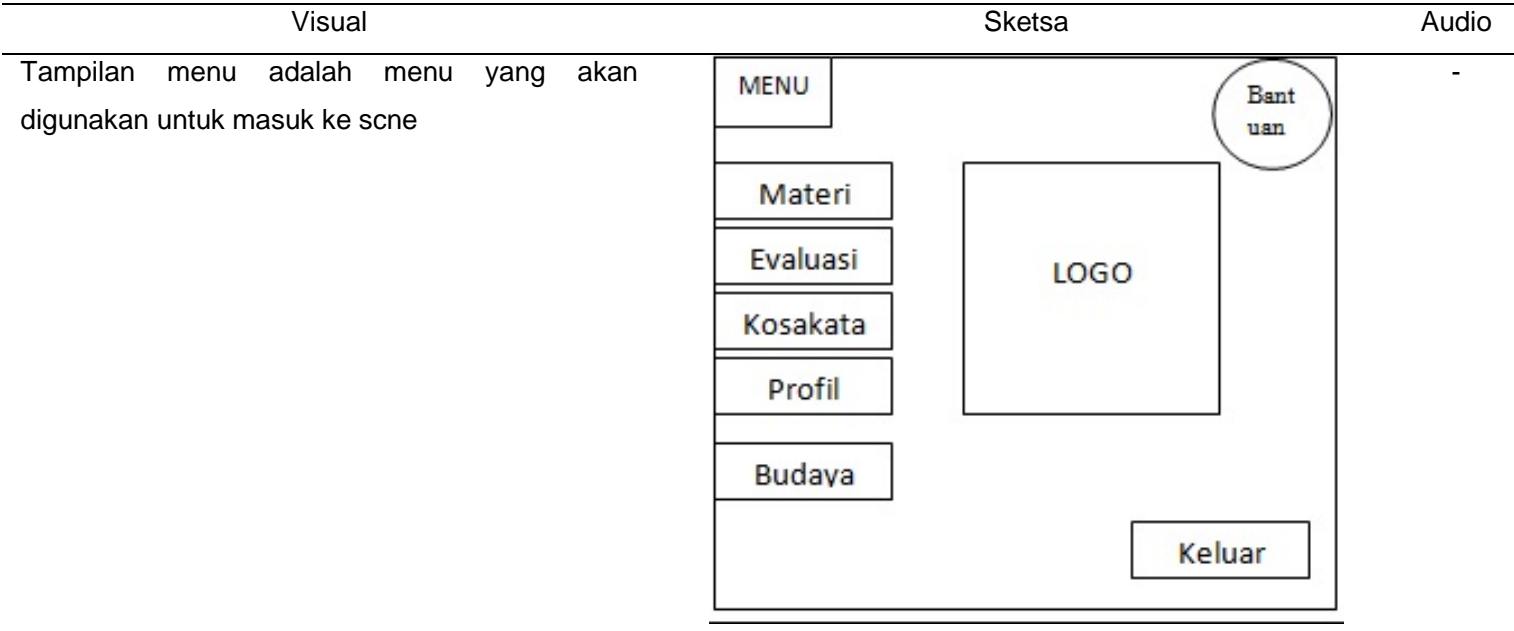


Berikut ini gambar storyboard menu materi berisikan menu-menu dari materi media pembelajaran Bahasa jepang seperti yang dijelaskan pada tabel berikut:

Tabel 3. Storyboard Menu Materi

\begin{tabular}{|c|c|c|c|}
\hline & \multicolumn{2}{|r|}{ Sketsa } & Audio \\
\hline \multirow[t]{5}{*}{$\begin{array}{l}\text { Tampilan menu materi yang } \\
\text { berisikan menu-menu dari materi } \\
\text { media pembelajaran Bahasa jepang }\end{array}$} & $\begin{array}{l}\text { MENU } \\
\text { MATERI }\end{array}$ & & \\
\hline & Huruf Hiragana & & \\
\hline & Huruf Katakana & & \\
\hline & Huruf Kanji & & \\
\hline & $\begin{array}{c}\text { Berbicara } \\
\text { Bahasa Jepang }\end{array}$ & & \\
\hline
\end{tabular}

Sumber: Hasil Penelitian (2019)

Berikut ini gambar storyboard menu materi berisikan menu Latihan dari menu evaluasi media pembelajaran Bahasa jepang seperti yang dijelaskan pada tabel berikut:

Tabel 4. Storyboard Menu Latihan Soal

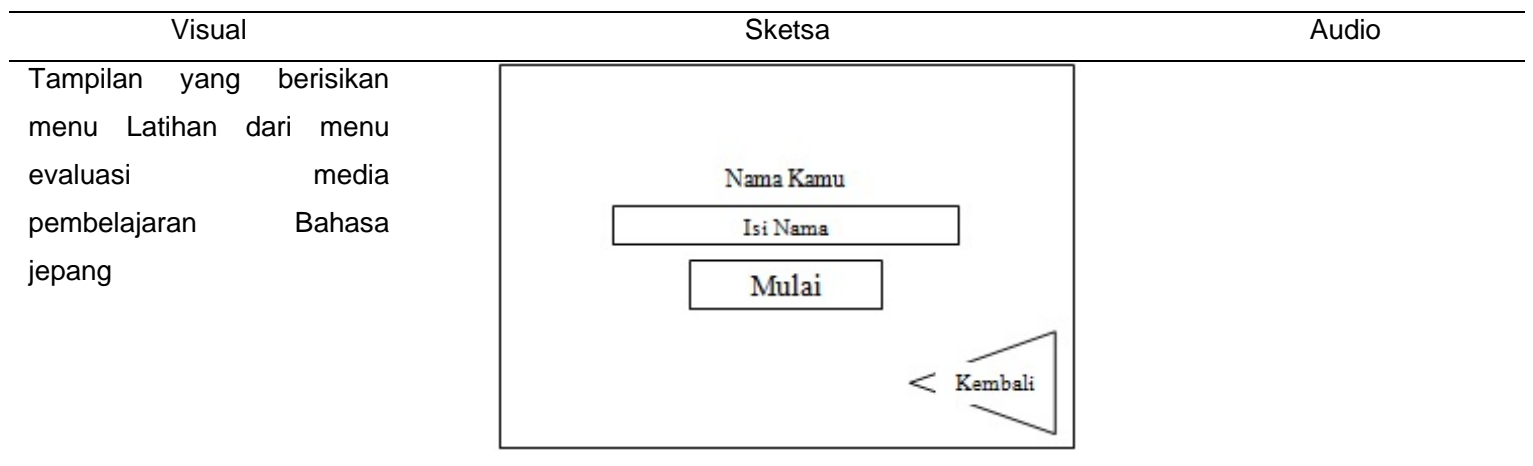

Sumber: Hasil Penelitian (2019)

\subsection{User Interface}

Berikut ini adalah user interface pada halaman intro :

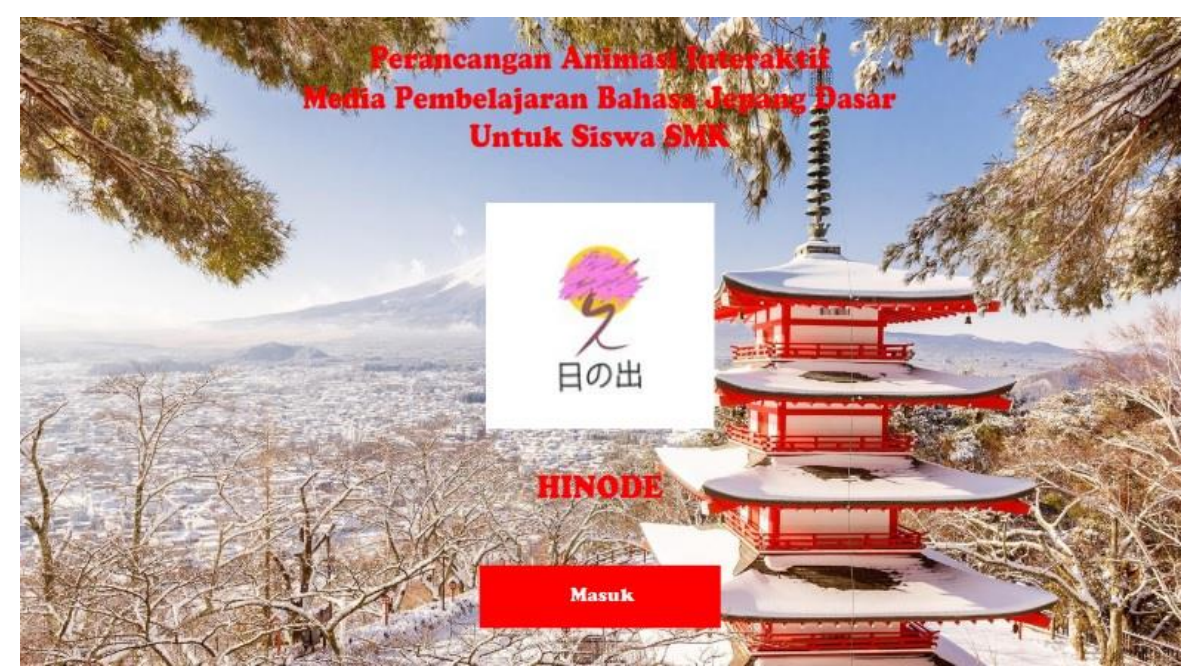


Sumber: Hasil Penelitian (2019)

Gambar 1. User Interface Intro

Berikut ini adalah user interface pada halaman menu utama :

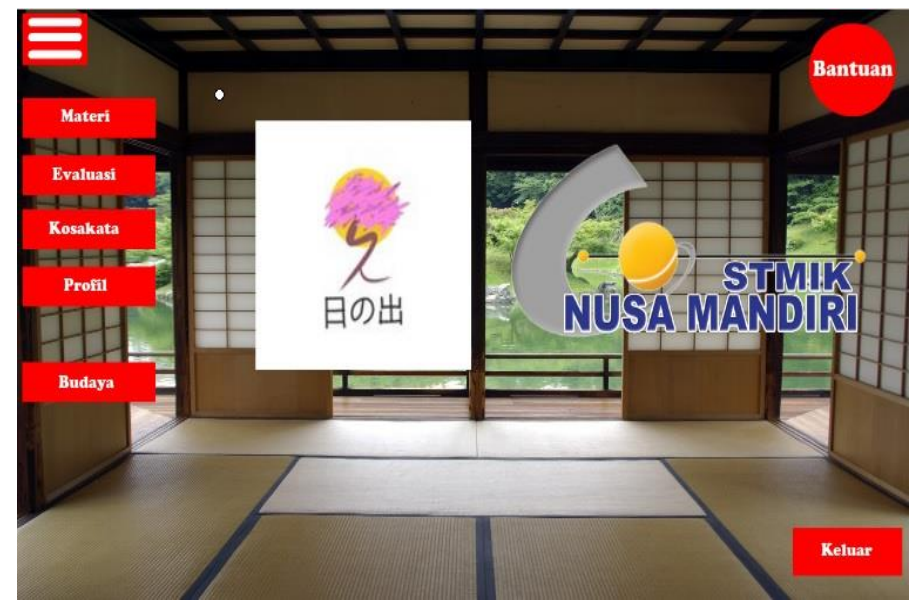

Sumber: Hasil Penelitian (2019)

Gambar 2. User Interface Menu Utama

Berikut ini adalah user interface pada halaman menu materi :

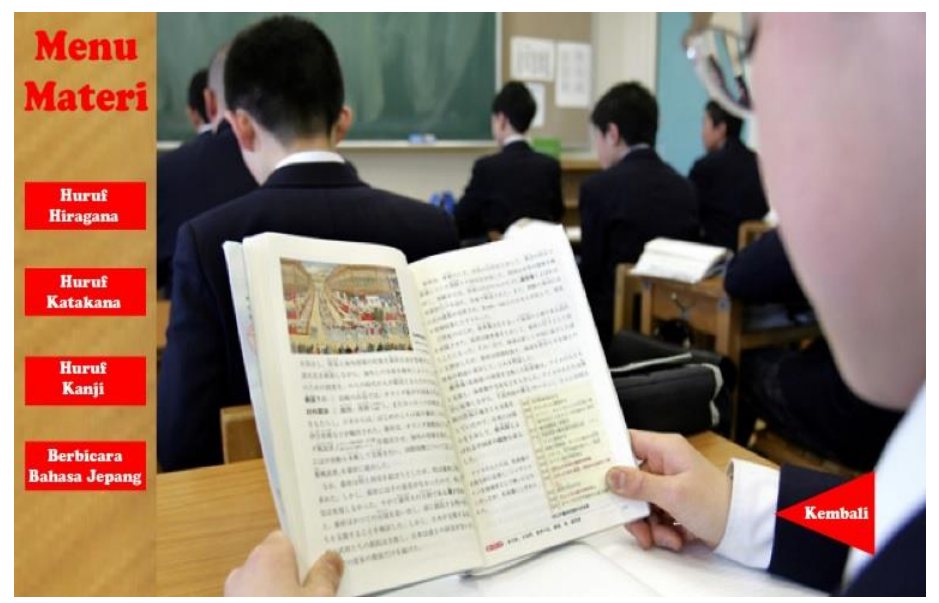

Sumber: Hasil Penelitian (2019)

Gambar 3. User Interface Menu Materi

Berikut ini adalah user interface pada halaman menu latihan soal:

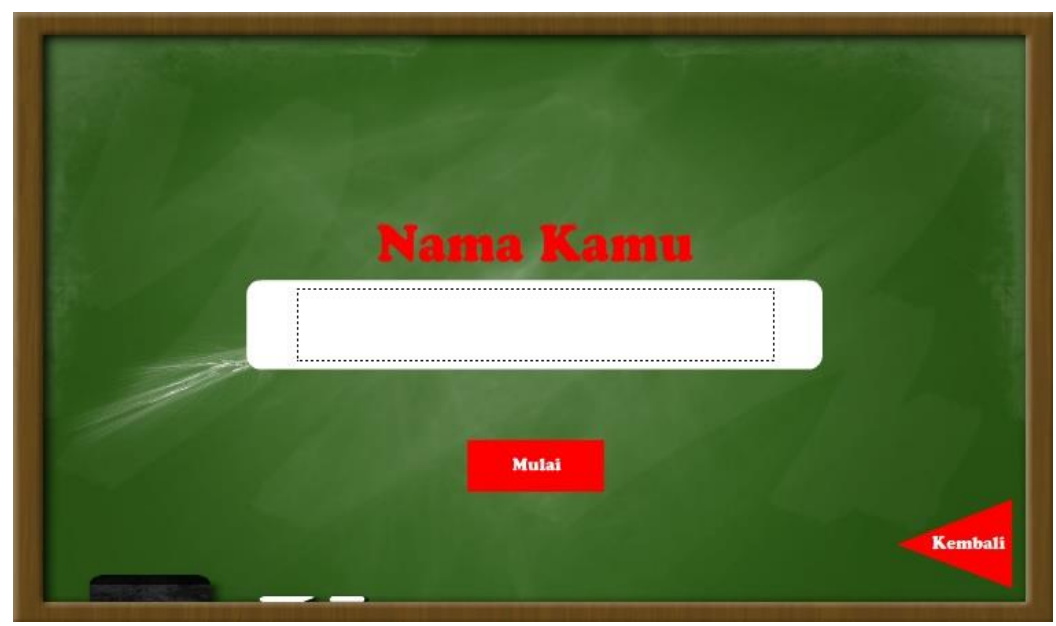


Gambar 4. User Interface Menu Latihan Soal

\subsection{State Transition Diagram}

Alur dari program animasi yang penulis rancang diantaranya adalah State Transition Diagram Menu Utama yaitu alur dari tampilan judul, menu utama yang berisikan 7 tombol yang setiap tombol memiliki output pembahasan yang berbeda jika diklik.

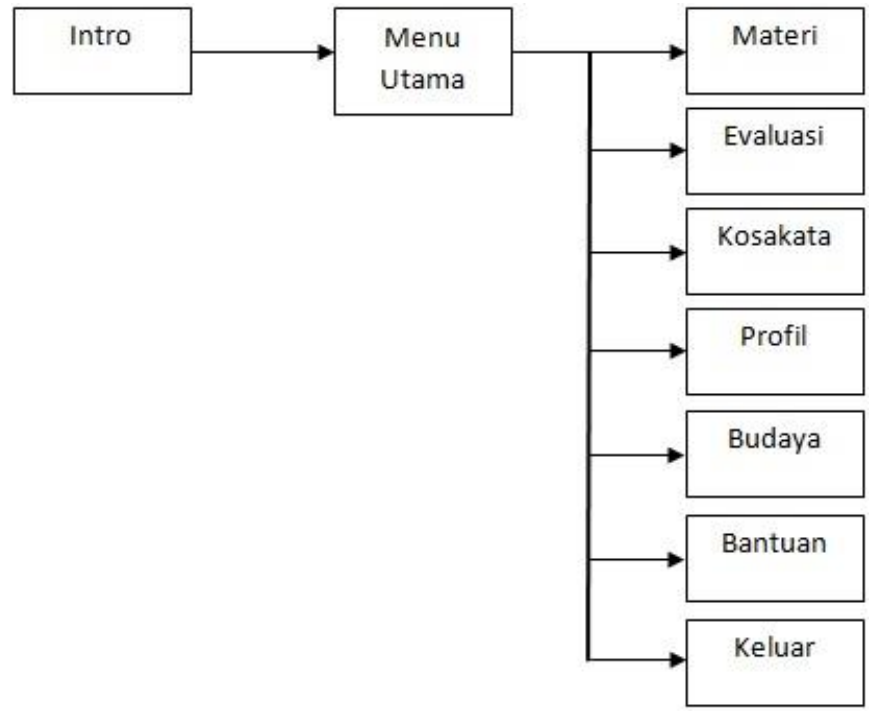

Sumber: Hasil Penelitian (2019)

Gambar 5. Scene Alur Menu Utama

\subsection{Black Box Testing}

Pengujian Black Box Testing adalah menguji fungsi perangkat lunak dari cara beroperasinya suatu program atau aplikasi(Jaya, 2018). Pengujian ini dilakukan untuk memastikan bahwa perintah masukan atau keluaran akan menjalankan proses yang benar dan menghasilkan output yang sesuai dengan yang diharapkan.

Tabel 5. Black Box Menu Utama

\begin{tabular}{|c|c|c|c|}
\hline Input/Event & Proses & Output/Next Stage & $\begin{array}{c}\text { Hasil } \\
\text { Pengujian }\end{array}$ \\
\hline $\begin{array}{c}\text { Tombol menu } \\
\text { materi }\end{array}$ & $\begin{array}{c}\text { on (release) }\{ \\
\text { gotoAndPlay("materi",1); } \\
\}\end{array}$ & $\begin{array}{l}\text { Menampilkan menu } \\
\text { materi }\end{array}$ & Sesuai \\
\hline $\begin{array}{c}\text { Tombol menu } \\
\text { evaluasi }\end{array}$ & $\begin{array}{c}\text { on (release) }\{ \\
\text { gotoAndPlay("evaluasi",1); }\}\end{array}$ & $\begin{array}{c}\text { Menampilkan menu } \\
\text { evaluasi }\end{array}$ & Sesuai \\
\hline $\begin{array}{c}\text { Tombol menu } \\
\text { kosakata }\end{array}$ & $\begin{array}{c}\text { on (release) }\{ \\
\text { gotoAndPlay("kosakata",1);\} }\end{array}$ & $\begin{array}{c}\text { Menampilkan menu } \\
\text { kosakata }\end{array}$ & Sesuai \\
\hline $\begin{array}{c}\text { Tombol menu } \\
\text { profil }\end{array}$ & $\begin{array}{c}\text { on (release) }\{ \\
\text { gotoAndPlay("profil",1); } \\
\}\end{array}$ & $\begin{array}{l}\text { Menampilkan menu } \\
\text { profil }\end{array}$ & Sesuai \\
\hline $\begin{array}{c}\text { Tombol menu } \\
\text { budaya }\end{array}$ & $\begin{array}{c}\text { on (release) }\{ \\
\text { gotoAndPlay("budaya",1); } \\
\}\end{array}$ & $\begin{array}{c}\text { Menampilkan menu } \\
\text { budaya }\end{array}$ & Sesuai \\
\hline Tombol menu & on (release) \{ & Menampilkan menu & Sesuai \\
\hline
\end{tabular}




\begin{tabular}{cccc}
\hline Input/Event & Proses & Output/Next Stage & $\begin{array}{c}\text { Hasil } \\
\text { Pengujian }\end{array}$ \\
\hline bantuan & gotoAndPlay("bantuan",1); & bantuan & \\
\hline Tombol keluar & on (release) \{ & Menu keluar & Sesuai \\
& fscommand ("quit","true"); & \\
Sumber: Hasil Penelitian (2019) & \} & \\
\end{tabular}

\section{Kesimpulan}

Dengan dibuatnya program animasi interaktif media pembelajaran bahasa jepang dasar untuk sekolah menengah kejuruan, dapat ditarik kesimpulan sebagai berikut: 1) Dengan adanya program animasi interaktif ini dapat menjadi media alternatif dalam pembelajaran bahasa jepang. 2) Dengan dibuatnya program animasi interaktif ini, maka siswa-siswi dapat menggunakan metode pembelajaran lebih mudah untuk dimengerti dan dapat menggunakannya untuk proses belajar mengajar. 3) Program animasi interaktif ini dapat digunakan tidak hanya untuk siswa-siswi saja melainkan untuk para pelajar yang ingin belajar bahasa jepang dasar. 4) Dengan adanya program animasi interaktif ini maka siswa-siswi dapat melihat simulasi tentang tata cara menulis huruf jepang dengan jelas dan benar. Program animasi interaktif media pembelajaran bahasa jepang dasar ini, soal dan isi materinya dapat disesuaikan dengan kebutuhan disekolah menengah kejuruan.

\section{Daftar Pustaka}

Ameliola, S., \& Dwiyudha Nugraha, H. (2013). Pemanfaatan Perkembangan Teknologi Informasi Dan Komunikasi Untuk Kemajuan Ppendidikan di Indonesia. Prosiding The 5th International Conference on Indonesian Studies: "Ethnicity and Globalization," 362-371.

Jaya, T. S. (2018). Pengujian Aplikasi dengan Metode Blackbox Testing Boundary Value Analysis (Studi Kasus: Kantor Digital Politeknik Negeri Lampung). Jurnal Informatika Pengembangan IT (JPIT), 3(2), 45-46. https://doi.org/10.30591/jpit.v3i1.647

Komarudin, R., \& Noor, R. R. (2017). Analisis Perancangan Media Pembelajaran Animasi Interaktif Mengenal Bahasa Jepang. Pilar Nusa Mandiri, 13(1), 12-20.

Nugroho, O., Dharmawan, D., \& Halim, A. (2012). Pengembangan Aplikasi Android Realtime Translation Untuk Menerjemahkan Bahasa Jepang ke Bahasa Indonesia. 1-12.

Purnama, B. E. (2012). Microsoft Word - 09 Pengembangan Multimedia Pembelajaran Interaktif Untuk Mata Kuliah Organisasi Komputer.doc. 4(2), 60-67.

Soepomo, P. (2013). Aplikasi Pengenalan Huruf Hangeul Berbasis Multimedia Interaktif. 1(1), 347-357. https://doi.org/10.12928/jstie.v1i1.2550 